\title{
Electron Beam Cold Hearth Refining of Investment Casting Superalloys \\ in a Large Production EB Furnace
}

Janine C. Borofka

Axel Johnson Metals, Inc. P.O. Box 529

Exton, PA, USA 19341
Eva Samuelsson and Gernant E. Maurer

Special Metals Corp.

Middle Settlement Road

New Hartford, NY, USA 13413

\begin{abstract}
Electron beam cold hearth remelting (EBCHR) is increasingly applied to the production of remelt stock for investment casting. In smaller EBCHR furnaces, remelt bars are cast one at a time. Because this method does not lend itself well to production in large EBCHR furnaces, this investigation evaluates a newly developed EB drum casting process and the characteristics of half-round remclt bars produced.

Processing parameters investigated were casting rate, mold size and configuration, and hot topping procedure. Half-round EBCHR drum cast bars of IN100 and PWA1422 were evaluated for structure, chemical composition and oxide cleanliness using the electron beam button test (EBBT).

Bars with good internal and surface integrity were produced applying combinations of hot topping and a surface glazing procedure. The results indicate that uniform chemical composition can be achieved within individual bars and within a heat. Oxide clcanliness was improved after EBCHR, but the greatest impact was made when the top surface of the bars were conditioned.
\end{abstract}




\section{Introduction}

Traditionally, remelt stock for investment casting superalloys is vacuum induction melted (VIM) and statically cast into $75-125 \mathrm{~mm}$ diameter remelt bars. Before shipment to the investment casting foundry, the bars are cropped, conditioned and sequentially identified. At the investment casting plant, additional preparation typically includes the breaking or cutting of the remelt bars to suit the particular requirements of the VIM investment casting furnace and mold.

To ensure good quality castings and to minimize scrap, uniform chemical composition is required throughout the VIM heat, as well as heat-to-heat. Physical characteristics of remelt stock include good surface quality and minimum internal pipe which minimize entrapment of plant dust and cutting swarf. In addition, a minimum content of non-metallic inclusions (both nitrides and oxides) is required for casting cleanliness requirements, optimum casting yields and reduced in-service part failures.

More recently developed processes for superalloy remelt stock production utilize electron beam cold hearth refining (EBCHR). Small electron beam (EB) furnaces (250-400 kW), watercooled copper hearths and water-cooled copper collar molds are used to produce remelt bars one at a time by semi-continuous casting. Large withdrawal increments may be used to reduce hot tearing (1).

In addition to ceramic-free processing, EBCHR benefits superalloys through improved cleanliness as a result of the removal of oxide and nitride inclusions (dross). Because the improvement is evident in the products even after VIM casting into a ceramic mold, EBCHR remelt stock is now specified for certain advanced single crystal superalloy airfoils and is justified by improved production yields and mechanical properties. Another benefit of dross reduction is the decrease in oxygen and nitrogen contents, which in turn increases the utilization of revert. EB refined revert has been shown to be as castable as virgin metal (2), a fact that may be due to a change in the carbide nucleation mechanism caused by TiN removal. A drawback to EBCHR is the loss of volatile elements such as chromium. However, this loss can be compensated for by enriching the input material or by in-process additions (3).

In large production EBCHR furnaces such as those at AJMI (2400-3300 kW), casting remelt stock bars one at a time is not economical since the size of the furnace necessitates high production rates. Initial work at AJMI focused on simultaneous casting of multiple small diameter bars in a water-cooled copper collar mold with semi-continuous withdrawal. However, success was limited to superalloys that were not prone to hot tearing so an alternate process was developed for casting remelt stock. A casting drum, which holds a series of small diameter, water-cooled copper half-round molds is installed in the EB furnace chamber at the end of the refining hearth. As the drum rotates, the molds fill, solidify, and empty, to bc refilled again as shown in Figure 1. The products are in the shape of half cylinders, or halfround bars.

Because the molds fill statically, hot tearing is avoided, but cold shutting can occur. Additional EB power may be directed to the mold during filling to maintain a thermal balance which discourages cold shutting. The drum cast bars may be hot topped to minimize internal shrinkage by applying EB power to a full mold and maintaining a liquid pool at the surface, and allowing solidification to proceed from the bottom upward.

The pour stream and refining in the hearth are uninterrupted during the drum casting, so that steady state casting and refining conditions are maintained. Non-metallic inclusions which float to the surface of the molten metal as it flows through the hearth are prevented from entering the mold by electron beam induced thermal stirring currents. The surface of both the hearth and the molds can be continuously observed or video-taped during casting, to verify the cleanliness of the metal. 

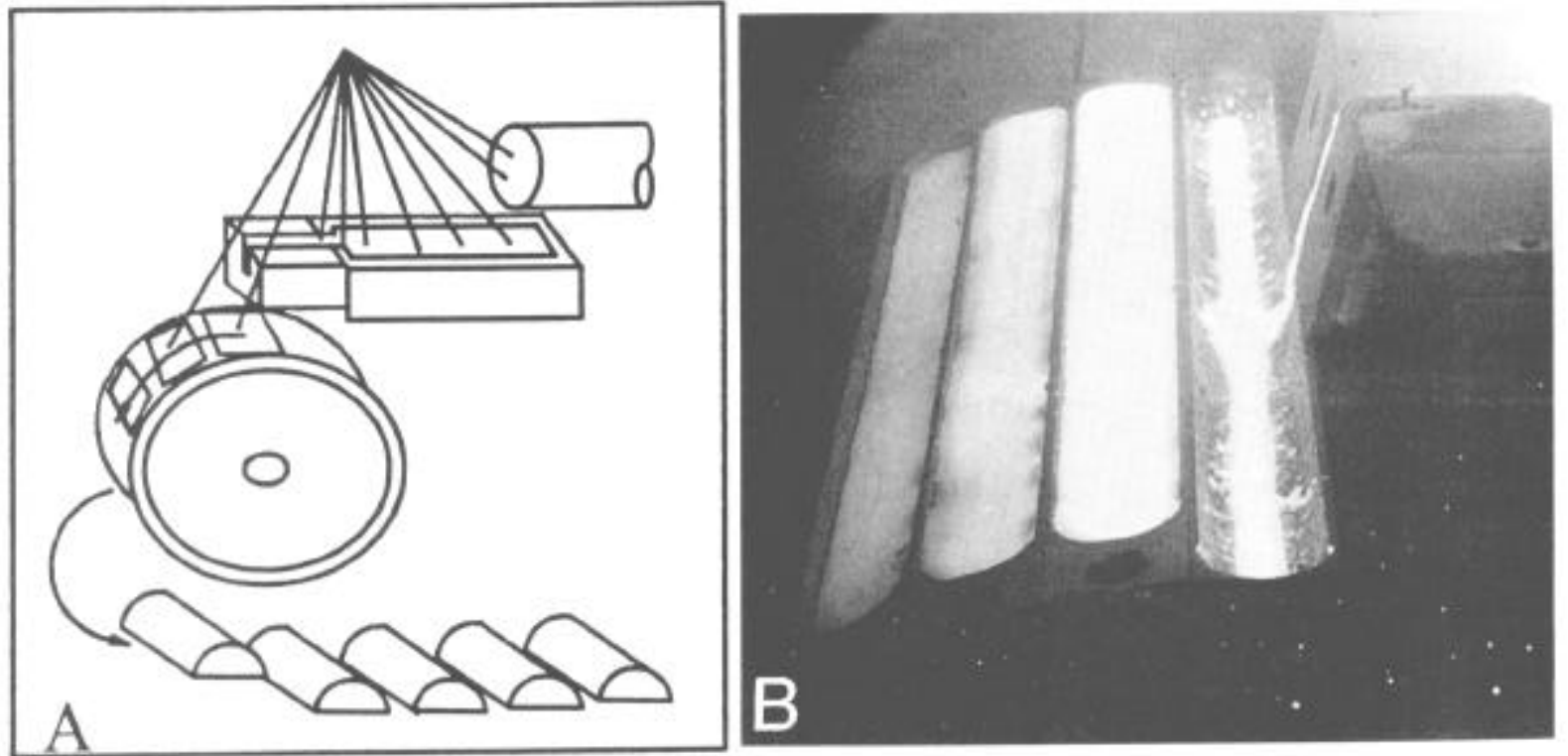

Figure 1. EB Drum Casting. (a) Schematic showing VIM ingot, water-cooled copper hearth, pour lip, drum with water-cooled copper molds, electron beams and half-round bar product; (b) Photograph showing filling, hot topping and solidification of molds.

\section{Experimental Procedure}

Parameters investigated during EBCHR drum casting trials were input material (alloy, cleanliness and preparation), casting rate, mold size and configuration, and hot topping procedure. The EB refined metal was analyzed for structure, chemistry and cleanliness.

Two types of casting superalloys, one for polycrystalline and the other for directional solidification (IN100 and PWA1422, respectively) were evaluated. IN100 was chosen since large quantities of "dirty" alloy cannot presently be reverted using VIM processing, and is sold to the non-aerospace industry. Particularly with rising cobalt prices, EBCHR is an attractive alternative. PWA 1422 presented an opportunity to evaluate the effect of oxidenitride density on flotation refining in the hearth. The major oxide former in PWA1422 is hafnium, in contrast to aluminum, the major oxide former in IN100. Nominal compositions are given in Table I.

The input material was VIM cast into either large $(355-430 \mathrm{~mm}$ diameter) or small diameter ingots (75 $\mathrm{mm}$ diameter). The smaller bars were assembled by welding for feeding into the EB furnace. Some ingots were surface conditioned before EB melting; others had as-cast surfaces. Two heats of IN100 were made from "dirty" alloy or revert which was out of specification in oxygen and nitrogen. All input material was enriched in chromium.

Casting rates, as calculated by the mold volume and filling time, were aimed at $1000 \mathrm{lb} / \mathrm{hr}$. Some variation around that rate occurred, especially at the start up of casting. Faster rates increased the possibility of spillover as the rotational speed of the drum increased, while slower rates increased chromium evaporation due to the longer residence times. Erratic casting rates resulted in excessive chromium variability in the bars.

Table 1. Nominal Compositions of IN100 and PWA1422 (Weight \%), balance Ni.

\begin{tabular}{lllllllllllll}
\hline & $\underline{\mathrm{Cr}}$ & $\underline{\mathrm{C}}$ & $\underline{\mathrm{Mo}}$ & $\underline{\mathrm{W}}$ & $\underline{\mathrm{Nb}}$ & $\underline{\mathrm{Al}}$ & $\underline{\mathrm{Ti}}$ & $\underline{\mathrm{C}}$ & $\underline{\mathrm{B}}$ & $\underline{\mathrm{Z}_{r}}$ & $\underline{\mathrm{V}}$ & $\underline{\mathrm{H}}$ \\
IN100 & 10.0 & 15.0 & 3.0 & - & - & 5.5 & 4.7 & 0.18 & 0.014 & 0.06 & 1.0 & $\ldots$ \\
PWA1422 & 8.5 & 9.5 & - & 12.0 & 1.0 & 5.0 & 2.0 & 0.13 & 0.015 & $\ldots$ & $\ldots$ & 2.0 \\
\hline
\end{tabular}



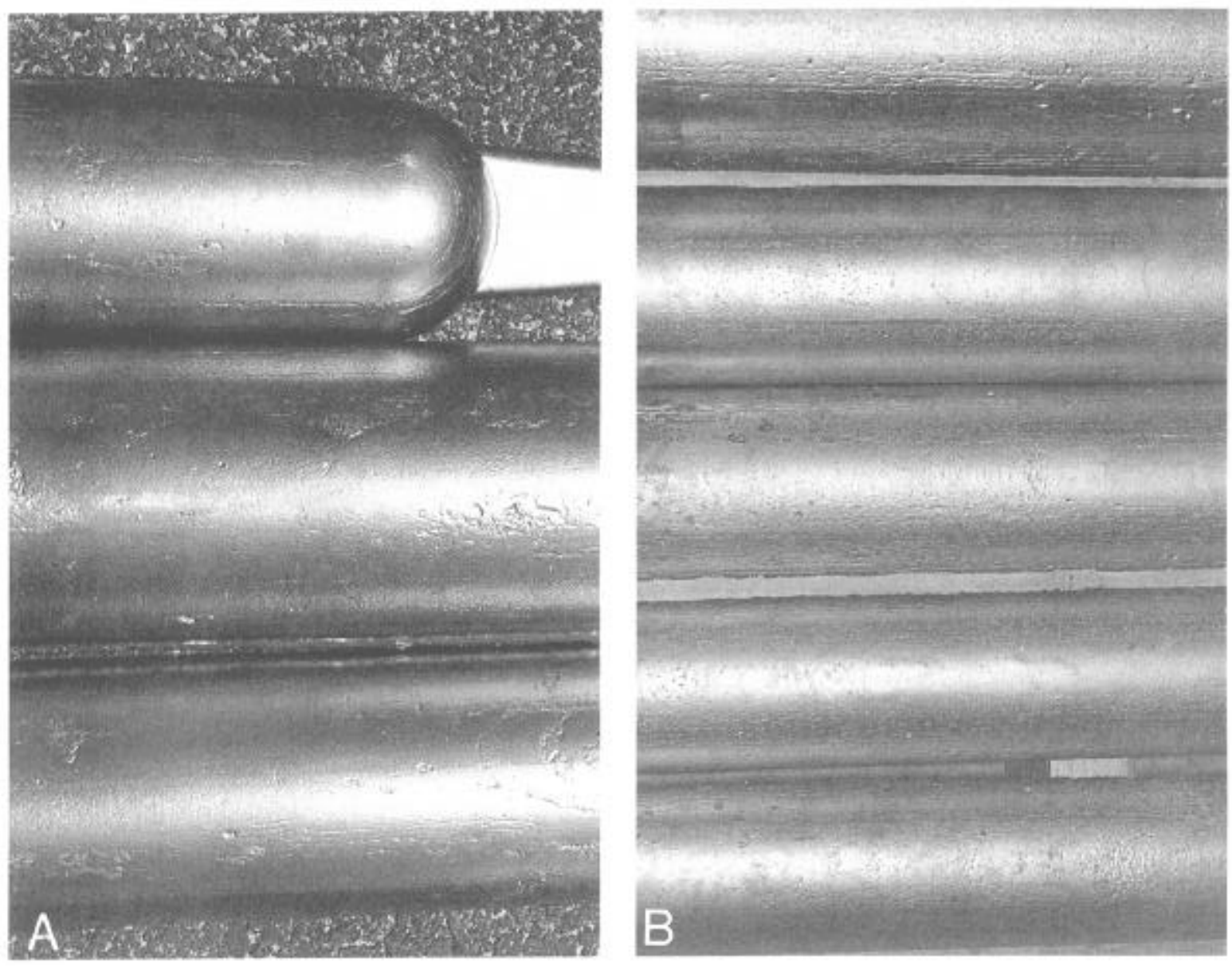

Figure 2. As-cast bottom surfaces of EB drum cast bars, 75 and $89 \mathrm{~mm}$ molds (a) IN100; (b) PWA1422.

The molds were either half-round cross-sections (75 or $89 \mathrm{~mm}$ wide) or deeper modified parabola cross-sections ( $89 \mathrm{~mm}$ wide). The deeper molds were designed to increase the linear density of the bars while still allowing the bars to drop out of the molds. Some molds were equipped with ejection pins to assist the release of the bars from the mold.

Various casting and hot topping procedures were used. Some bars were cast without additional EB power directed to the mold, while others had power during filling but not afterward (not hot topped). In other cases, the bars were hot topped by EB power to the mold. A fourth procedure consisted of hot topping followed by "glazing," which consisted of a short, high intensity application of power to the top surface of the bar after hot topping and solidification, long enough to re-liquify only a shallow layer of metal and seal off any surface-connected porosity.

\section{Structure and Effect of Hot Topping}

Photographs of the as-cast surfaces of EB drum cast bars are shown in Figures 2 and 3. The bottom surfaces of the bars are smooth with cold shuts. Bars cast without EB power directed to the mold did not fill evenly and had unacceptable amounts of cold shutting. Bars cast with EB power in the mold had only small cold shuts and laps as shown in Figure 2.

The top surface morphologies varied with hot topping procedure and corresponded to internal structure. Photographs of macro-etched sections of bars are shown in Figure 4 and described below. 

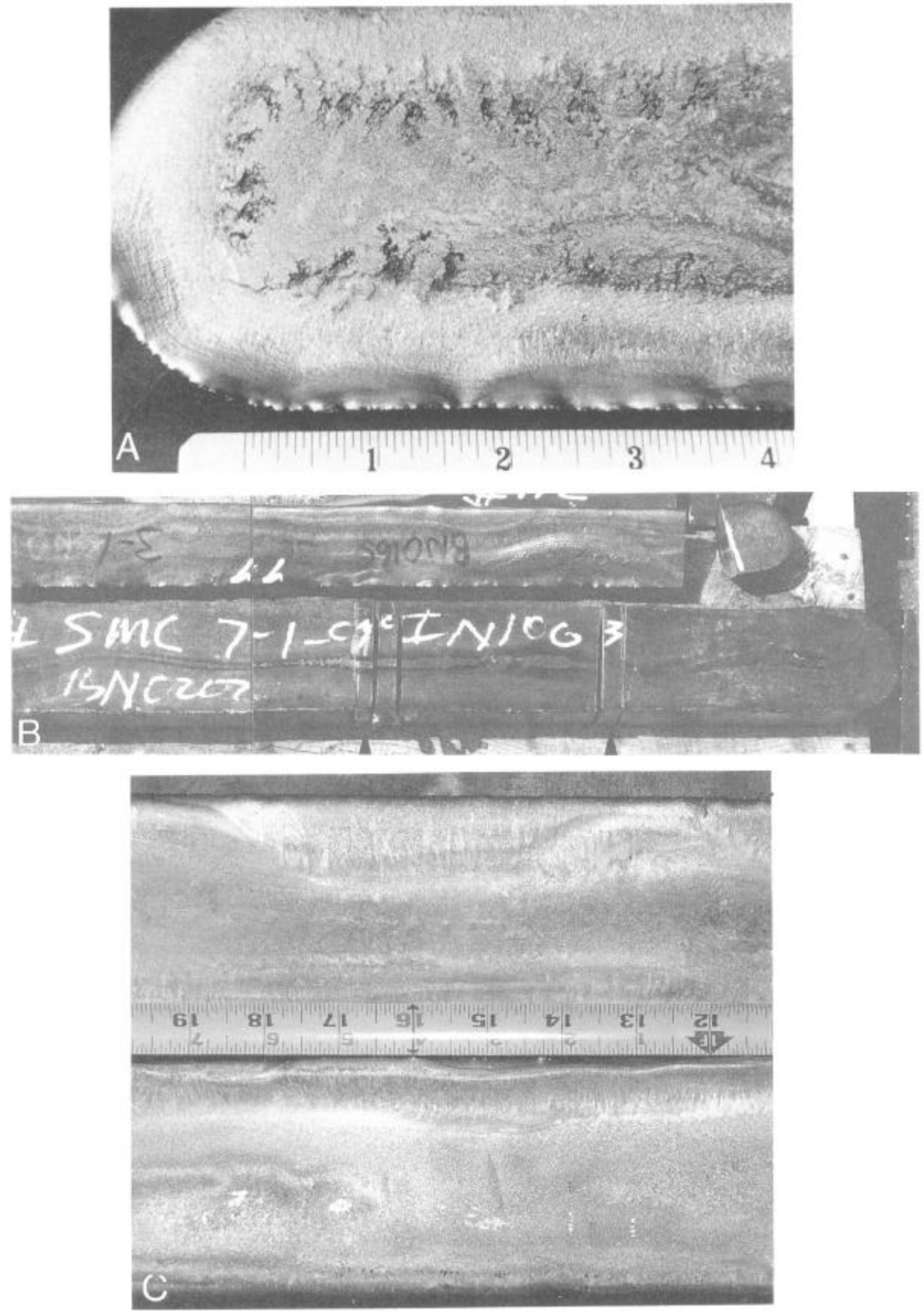

Figure 3. As-cast top surfaces of EB drum cast bars. (a) IN100 $75 \mathrm{~mm}$ mold, inadequate hot top; (b) IN100 $89 \mathrm{~mm}$ mold, hot topped; (c) PWA1422 $75 \mathrm{~mm}$ mold, hot topped and glazed. 

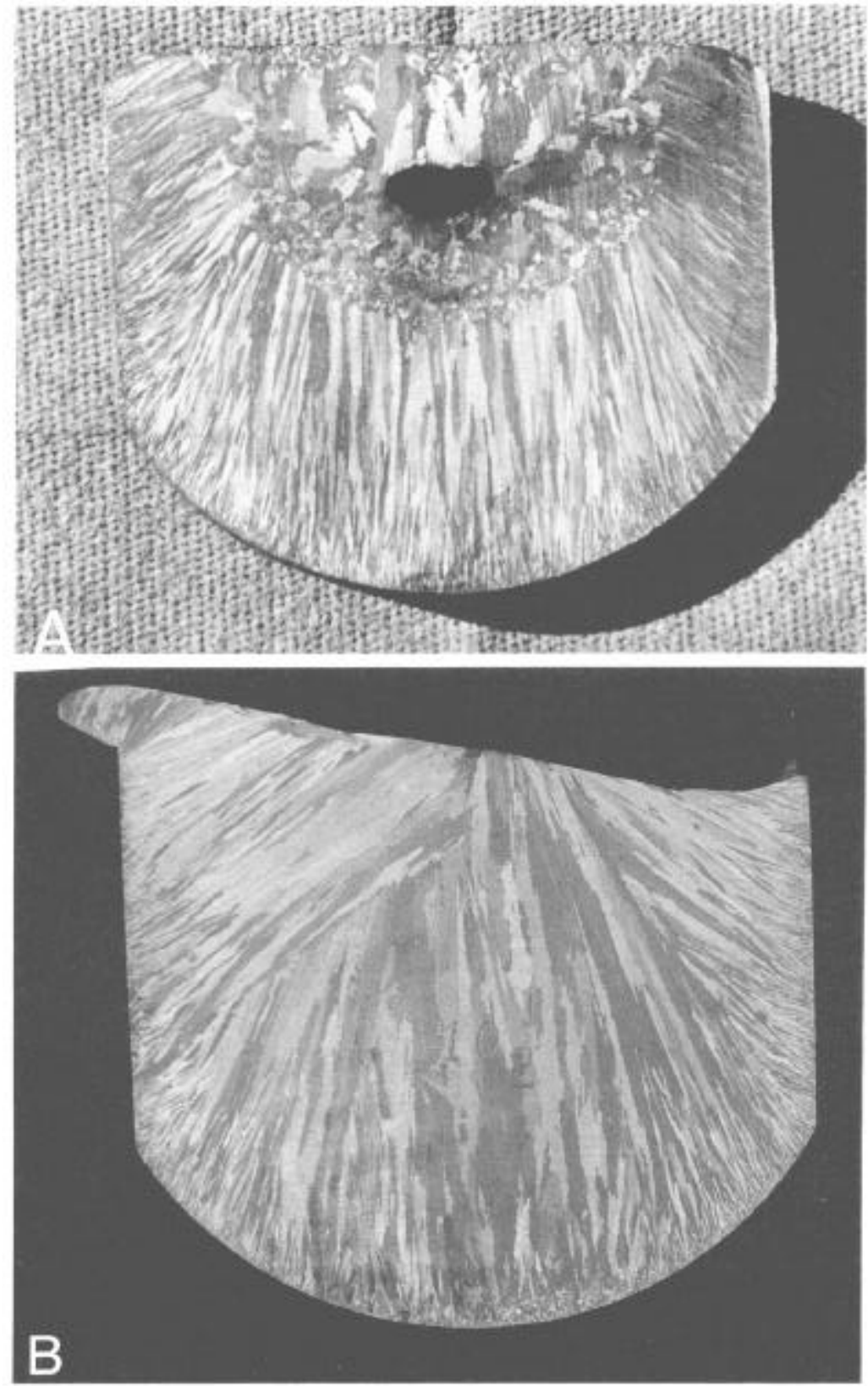

Figure 4. Macroetched cross-sections of EB drum-cast bars. (a) IN100, $89 \mathrm{~mm}$ deep mold, no hot top. Note large interval void; (b) IN100, $89 \mathrm{~mm}$ deep mold, hot topped (continued next page).

Not Hot Topped. Bars of IN100 and PWA1422 which were allowed to cool without hot topping typically had wide, smooth caps edged on either side by narrow porous bands. The outside edges show evidence of columnar grains (Figure 3a). In transverse cross-section, the cap corresponds to a equiaxed region which delineates the molten pool remaining when the mold indexed out of the filling position. The midradial regions consist of columnar grains which solidified from the bottom upward and inward. Between the equiaxed and columnar regions is a small gap, which appears rough and porous at the surface. At the bottom edges of the bar is a very fine grained region which had solidified rapidly on contact with the watercooled copper mold. Some sections showed evidence of gross internal porosity, which demonstrated the need for hot topping.

Hot Topped. Bars of both INI00 and PWA1422 were hot topped for varying lengths of time and amounts of EB power. In the extreme, the additional heat added during hot topping resulted in spill over because the metal in the mold did not solidify before the mold was canted as the drum rotated. Bars which were properly hot topped had no more than a thin 

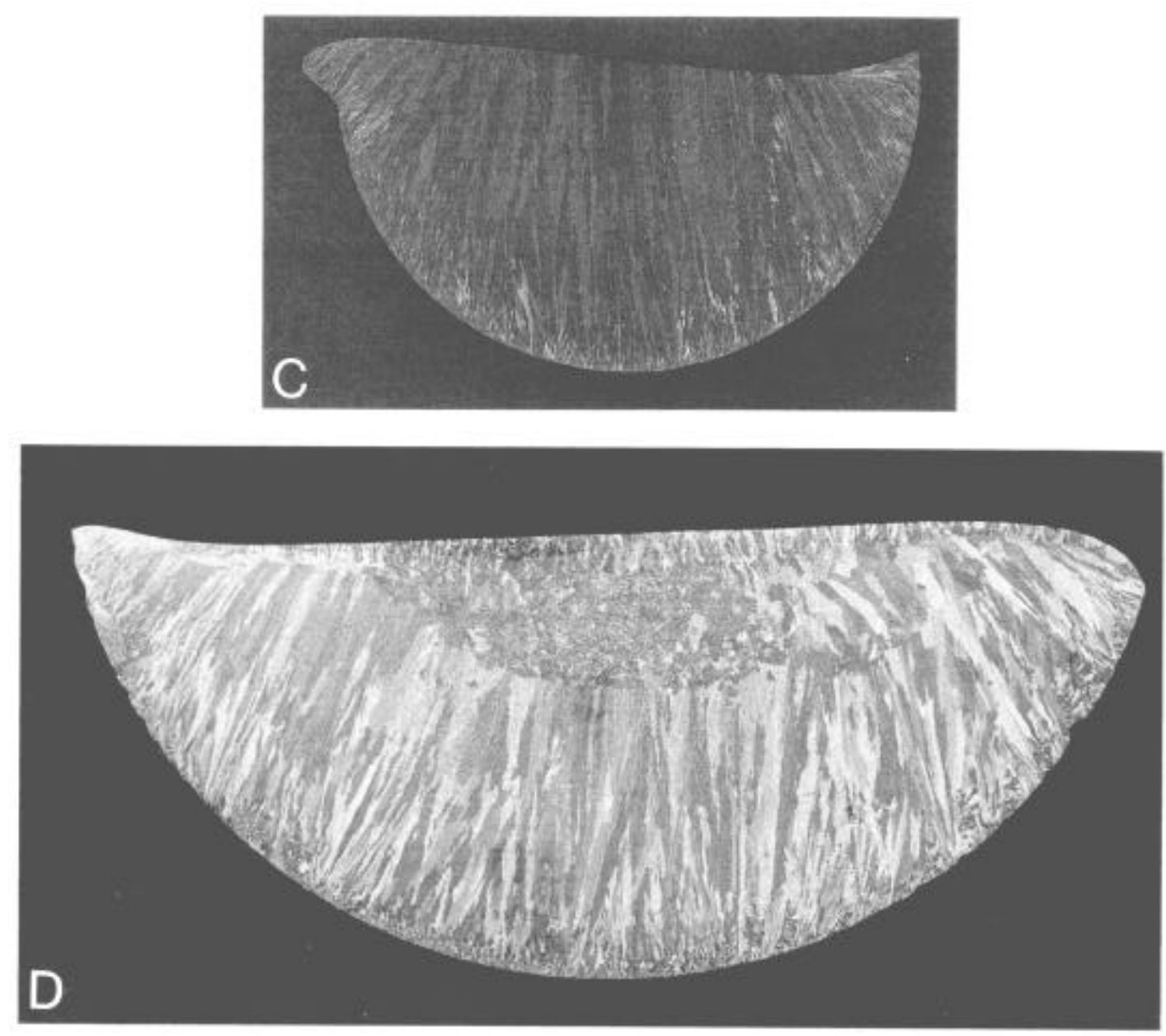

Figure 4. (continued) Macroetched cross-sections of EB drum-cast bars. (c) IN100, $75 \mathrm{~mm}$ half-round mold, hot top; (d) PWA1422, $89 \mathrm{~mm}$ half-round mold, hot top and glazing.

cap on the top surface (Figures 3b), and no internal or surface connected porosity (Figures $4 \mathrm{~b}$ and $4 \mathrm{c}$ ). The molten pool, as evidenced by the equiaxed region in the cross-section, was smaller when the bar solidified and shrinkage porosity was minimized.

Hot Topped and "Glazed." Bars of PWA1422 which were glazed in addition to hot topping had a wide smooth cap on the top where a thin surface layer had been remelted and solidified quickly (Figure 3c). In the extreme, the glazing operation resulted in spillover when too much metal was remelted. Because the hot top was abbreviated to allow the metal to solidify before glazing, the mold pool was evidently deeper at final solidification and fine internal shrinkage porosity persisted in some bars. However, no large cavities were observed and all surfaceconnected porosity was eliminated.

\section{Chemistry}

Figure 5 shows variation in chromium, the most volatile element, in one heat of drum cast IN100. Chromium loss reached steady state after casting less than $45 \mathrm{~kg}$ of metal. Multiple samples were taken from some bars (longitudinally and transversely), and did not show evidence of segregation end-to-end or through the thickness of the bars. Results are shown in Table II.

Reductions of nitrogen and oxygen were observed after EBCHR. For example, an out-ofspecification heat of IN100 dropped from $22 \mathrm{ppm}$ nitrogen and $12 \mathrm{ppm}$ oxygen to 12 and 8 ppm, respectively. A heat of PWA 1422 dropped from $8 \mathrm{ppm}$ nitrogen and $7 \mathrm{ppm}$ oxygen to 6 and 2 ppm, respectively. 


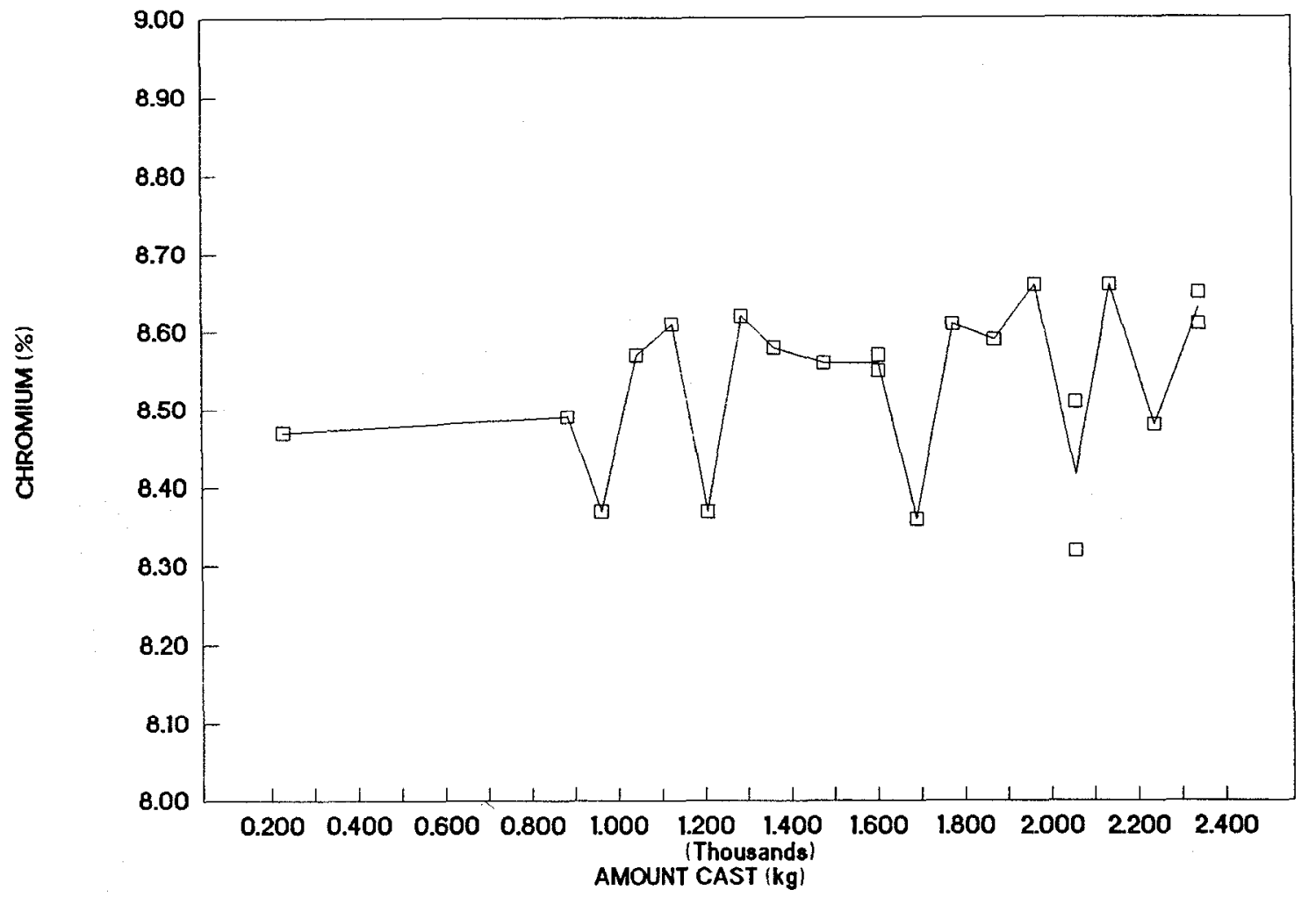

Figurc 5. Chromium variation in a subscale heat of IN100. Multiple samples taken from some bar heats.

Table II. Chemical Analysis of Multiple Locations from IN100 EB Drum Cast Bars, Balance Ni.

\begin{tabular}{|c|c|c|c|c|c|c|c|c|c|c|c|}
\hline $\begin{array}{l}\text { Location } \\
\text { within bar }\end{array}$ & $\begin{array}{l}\mathbf{N} \\
\text { ppm }\end{array}$ & $\begin{array}{l}\mathrm{O} \\
\mathrm{ppm}\end{array}$ & $\begin{array}{l}\mathbf{S} \\
\text { ppm }\end{array}$ & $\begin{array}{l}\mathrm{Cr} \\
\%\end{array}$ & $\begin{array}{l}\text { Co } \\
\%\end{array}$ & $\underset{\%}{\mathrm{Mo}}$ & $\begin{array}{l}\mathrm{Al} \\
\%\end{array}$ & $\begin{array}{l}\mathrm{Ti} \\
\%\end{array}$ & $\begin{array}{l}\mathrm{C} \\
\%\end{array}$ & $\begin{array}{l}\mathrm{Zr} \\
\%\end{array}$ & $\begin{array}{l}\mathrm{V} \\
\%\end{array}$ \\
\hline $\begin{array}{l}\text { end } \\
\text { center } \\
\text { end } \\
\text { top } \\
\text { mid top } \\
\text { mid bottom } \\
\text { bottom }\end{array}$ & $\begin{array}{l}10 \\
11 \\
10\end{array}$ & $\begin{array}{l}6 \\
6 \\
6\end{array}$ & $\begin{array}{c}10 \\
4 \\
7\end{array}$ & $\begin{array}{l}9.18 \\
9.24 \\
9.13 \\
9.38 \\
9.24 \\
9.20 \\
9.17\end{array}$ & $\begin{array}{l}14.34 \\
14.34 \\
14.41 \\
14.66 \\
14.38 \\
14.35 \\
14.32\end{array}$ & $\begin{array}{l}2.99 \\
2.99 \\
2.99 \\
2.91 \\
3.00 \\
3.00 \\
2.98\end{array}$ & $\begin{array}{l}5.47 \\
5.46 \\
5.50 \\
5.49 \\
5.48 \\
5.50 \\
5.44\end{array}$ & $\begin{array}{l}4.55 \\
4.55 \\
4.55 \\
4.11 \\
4.57 \\
4.59 \\
4.56\end{array}$ & $\begin{array}{l}0.16 \\
0.16 \\
0.16\end{array}$ & $\begin{array}{l}0.06 \\
0.06 \\
0.06 \\
0.04 \\
0.06 \\
0.06 \\
0.06\end{array}$ & $\begin{array}{l}0.77 \\
0.77 \\
0.77 \\
0.79 \\
0.77 \\
0.78 \\
0.78\end{array}$ \\
\hline
\end{tabular}

\section{Cleanliness Evaluation}

Samples from VIM heats and EBCHR heats were evaluated by electron beam button cleanliness testing (EBBT) to determine the reduction in oxide content after EBCHR. A general description of EBBT has been given by Blichmann et al. (4). The VIM samples were prepared by thoroughly grinding using non-oxide grinding media followed by ultrasonic cleaning. No porosity remained in the VIM samples. The EBCHR samples were prepared using various methods to evaluate the surface cleanliness resulting from the drum casting procedure. Table III describes the sample preparation. The change in cleanliness between starting VIM heats and EBCHR product is summarized in Figure 6 for both IN100 and PWA1422.

EBCHR improves the "internal" cleanliness of the material by at least one order of magnitude. The maximum benefit from EBCHR is obtained when the surface of the half-round bars is removed, for instance by grinding, as represented by sample preparation methods $\mathrm{A}$ and $\mathrm{C}$. However, even when the cast surfaces were included in the EBBT samples, a 50\% improvement in cleanliness was obtained indicating that EBCHR process development may be sufficient to produce a high-quality product without the need for surface conditioning. For example, IN100 analyzed using method B still shows a 50\% improvement in cleanliness. 


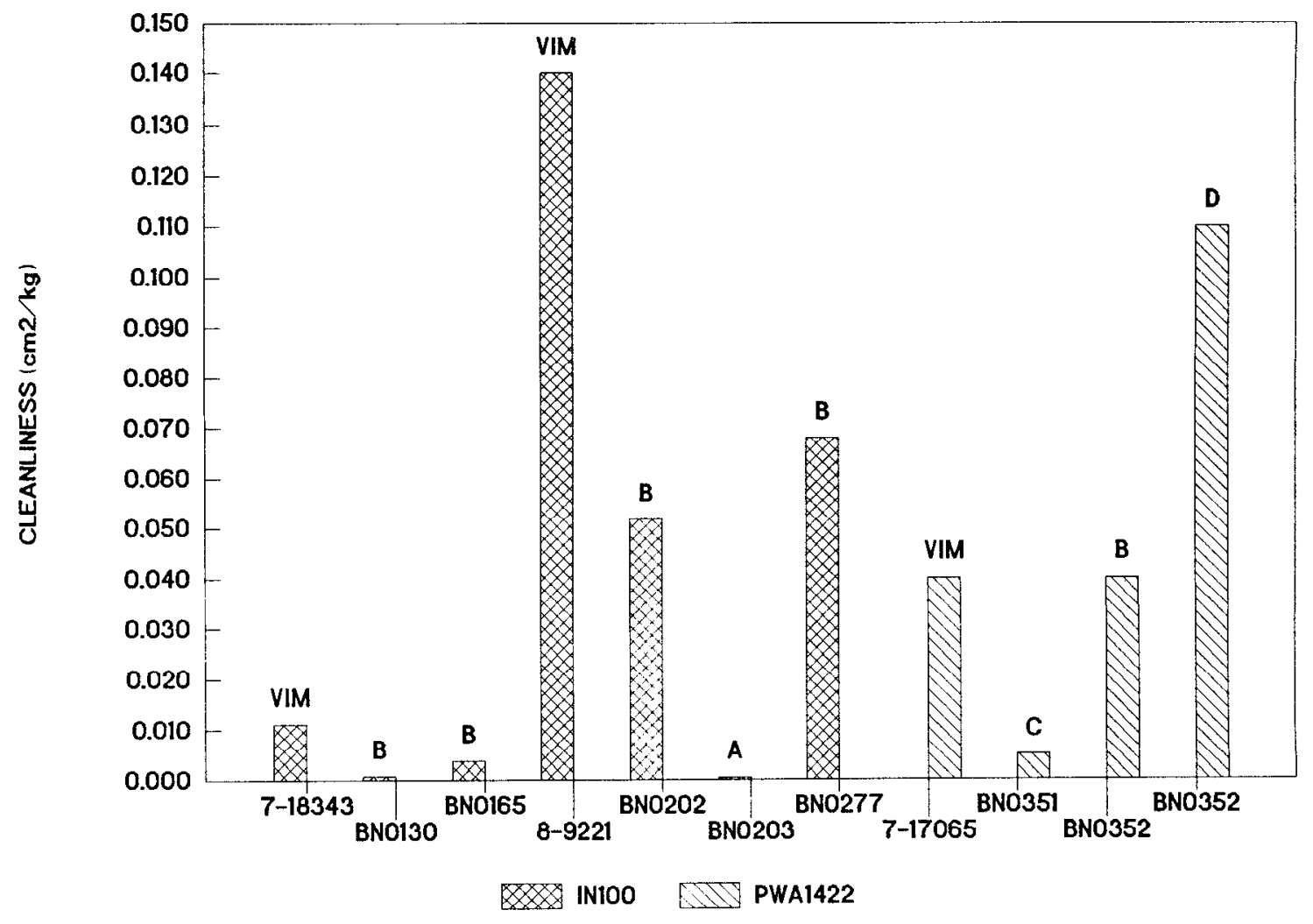

Figure 6. EBBT oxide cleanliness ratings for VIM feedstock and EBCHR material of IN100 and PWA1422. Each VIM heat was used as feed stock for the EBCHR heats shown to the right. See Table III for description of sample preparation methods A, $\mathrm{B}, \mathrm{C}$ and $\mathrm{D}$ for the EBCHR material.

Table III. Procedures for sample preparation for EBCHR melted material prior to EBBT.

Method Description

A Top of half-round slice cut off. Cut surfaces polished. Bottom surface as-cast.

B All cast surfaces including the top, only ultrasonically cleaned. Cut faces of slice polished.

C All surfaces thoroughly ground and polished. No porosity included.

D Sample grit blast then dipped in acid.

The improvement in internal cleanliness of the PWA1422 remelt ingots indicates that the high density hafnium oxides are removed by the EBCHR process. Two mechanisms probably operate: oxides remain on the surface of the hearth due to surface tension, where they are either pushed to the sides of the hearth or evaporate when hit by the electron beam; in addition, the oxide phase may consist of a mixture of alumina and hafnium oxides which has a density lower than the metal, retaining them on the surface. The higher oxide content of the samples prepared by grit blasting and acid dipping (method D) is probably due to contamination by the preparation method. 


\section{Conclusions}

- Large EB furnace refining of superalloys results in superior melt cleanliness even at higher casting rates due to the larger hearth and extended residence time.

- The drum casting process is capable of producing high quality, chemically homogeneous remelt stock and sound bars in the form of half cylinders that could be attached together to provide full round bars similar to the standard remelt stock in use today. The top surface morphology and condition can be used as a quality indicator.

- The EBBT cleanliness results indicate EBCHR ingots may not need conditioning prior to use. However, superior cleanliness results were obtained when the top surface of the ingots were surface ground.

- The EBBT cleanliness results indicated that inclusion density may not be a strong factor. Surface tension-related buoyancy may be a significant refining mechanism.

\section{$\underline{\text { References }}$}

(1) J.H.C. Lowe, "Continuous Casting Methods and Ingots Produced Thereby." U.S. Patent No. 4,641,704; February 10, 1989.

(2) D. Hartmann, U. Muerrle and M. Krehl, "Electron Beam Melting and Refining of Superalloys." In the proceedings of the Conference Electron Beam Melting and Refining: State of the Art 1989, Part II, ed. R. Bakish, Bakish Materials Corp., Englewood, NJ, 1989, pp. 97-108.

(3) J.C. Borofka and C.H. Entrekin, "Recent Advances in Electron Beam Refining of NickelBase Superalloys." In the proceedings of the Conference Electron Beam Melting and Refining: State of the Art 1991, ed. R. Bakish, Bakish Materials Corp., Englewood, NJ, 1991, pp. 227-239.

(4) R.B. Blichmann, J.M. Moyer, M.J. Oruska, "An EB Button Melting Test for Evaluating the Cleanliness of René 95." ibid. 1989, pp. 58-67. 